\title{
Delivering contraceptive vaginal rings to breastfeeding women
}

Population Council

Follow this and additional works at: https://knowledgecommons.popcouncil.org/departments_sbsr-rh

Part of the Demography, Population, and Ecology Commons, Family, Life Course, and Society Commons, International Public Health Commons, and the Women's Health Commons How does access to this work benefit you? Let us know!

\section{Recommended Citation}

"Delivering contraceptive vaginal rings to breastfeeding women," Project brief. New York: Population Council, 2016. 


\section{DELIVERING CONTRACEPTIVE VAGINAL RINGS TO BREASTFEEDING WOMEN}

The Progesterone Vaginal Ring (PVR) is a user-controlled contraceptive that helps breastfeeding women safely and effectively space, delay, or limit their next pregnancy.

For the first six months after childbirth, exclusive breastfeeding provides effective contraception. However, many women do not or are unable to exclusively breastfeed. Once a woman stops breastfeeding, begins adding other foods or liquids to her infant's diet, or starts menstruating, she is at risk of becoming pregnant and must consider other contraceptive methods to meet her own family planning goals.

Of the 213 million pregnancies that occurred across the world in 2012, it is estimated that roughly $40 \%$-about 85 million-were unintended. ${ }^{1}$ Despite this high unmet need, access to safe, effective, and affordable family planning methods in low-resource settings is often limited or nonexistent-especially for postpartum breastfeeding women. For women seeking to space their births or limit future pregnancies, new methods that do not require significant health-care resources or infrastructure can help address the growing demand.

The Population Council and partners developed the PVR to help address the unmet need for contraception among breastfeeding women. The ring provides a convenient option that adds choices for new mothers and promotes optimal infant nutrition and health.

\section{HOW THE PVR WORKS}

The PVR releases a continuous low dose of the natural hormone progesterone, which reinforces the inhibitory effect of breastfeeding on ovulation and delays the return of the menstrual cycle, therefore preventing pregnancy. A woman can begin using the ring as early as four weeks after birth if her menstrual cycle has not returned. A single ring can be used for three months and can be replaced with a new ring up until the child's first birthday.

In clinical trials, the PVR was $98.5 \%$ effective in preventing pregnancy when used continuously by women who breastfeed at least four times a day, which motivates women to breastfeed regularly. The PVR is safe for both mothers and babies, with few side effects-some women reported cramping, weight gain, breast tenderness, and spotting. Most women report a high degree of satisfaction and acceptance using the ring. Also,

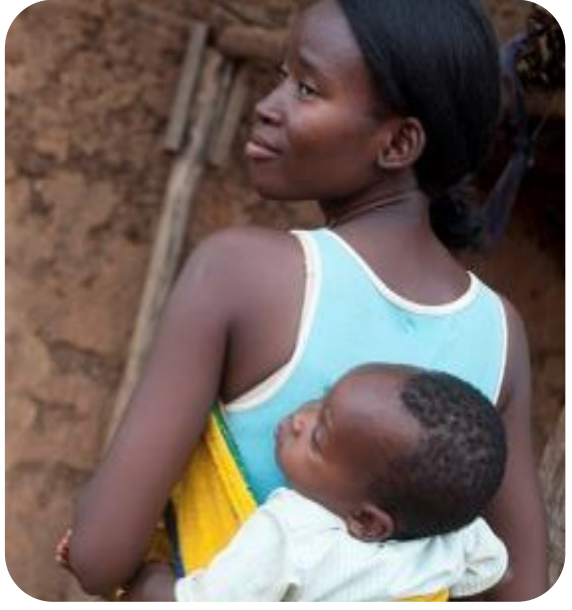

\section{ADVANCING NUTRITION
AND INFANT HEALTH WITH THE PVR: FAST FACTS}

Breastfeeding can lead to improved health and nutrition for newbornsand optimal breastfeeding saves lives.

As the PVR does not affect quality or amount of breast milk, it may be an attractive option for postpartum women who want a method that is minimally invasive, convenient, and discreet, without worrying about any potential impact on their health or the health of their infant.

The Population Council conducts research and delivers solutions that 
ongoing research suggests women may experience other benefits from breastfeeding, such as reduced risk of ovarian and breast cancer. ${ }^{2-3}$

Unlike other contraceptives suitable for breastfeeding women such as the IUD, the PVR is entirely under a woman's control-offering discreet protection from pregnancy, and giving the woman control to insert and remove the ring conveniently on her own. This reduces the need for involvement by skilled health-care providers, who often are in short supply in underserved settings, including rural areas where timely, convenient access to quality health-care may be scarce.

\section{ADDING VALUE TO THE METHOD MIX}

Traditionally, the lactational amenorrhea method (LAM) has been recognized as an effective way to delay return to fertility in breastfeeding women by delaying a woman's next menstrual cycle. ${ }^{4-10}$ However, research suggests very low numbers of breastfeeding women (less than 5\%) report compliance with LAM criteria. ${ }^{11}$

User-controlled methods such as vaginal rings represent an important advancement in family planning. The PVR is unique because it offers an accessible, easy-to-use method without requiring frequent trips to the pharmacy or ondemand access to a trained health-care provider. Similarly, rural communities need access to products that do not require sophisticated methods of storage to ensure the product remains safe, effective, and accessible. The PVR does not require special preparation or refrigeration.

\section{PROMOTING INFANT SURVIVAL}

Nearly 7 million children under the age of 5 die each year, mostly due to preventable causes. And newborn deaths represent nearly half of all deaths in children under age 5 . However, breastfed children have at least a six times greater chance of survival in the first months of life than nonbreastfed children, and the health benefits of breastfeeding are particularly critical in developing countries. ${ }^{12}$ The PVR not only provides contraceptive efficacy for new mothers, but also offers a method whereby the efficacy relies on optimal breastfeeding practices, holistically contributing to better outcomes for infants.

\section{INCREASING ACCESS AND MEETING CRITICAL DEVELOPMENT GOALS}

In 2015, countries worldwide adopted the Sustainable Development Goals-a set of critical goals setting the foundation of a new development agenda to be carried out over a 15-year period. The introduction of the PVR helps contribute to the success of several key goals including SDG 3 (ensuring healthy lives and promoting well-being at all ages) and SDG 5 (achieving gender equality and empowerment of all women and girls). ${ }^{13}$

And, with sustained investment in planning the introduction of a new method, health sectors play a major role in ensuring women can access a range of products that best meet their needs, when and where they need them. To help make this a reality, product developers and partners often employ what's called a "Total Market Approach." This approach brings together the public and private sectors (e.g., social marketing groups, NGOs, and commercial organizations). Through a highly coordinated effort, partners are able to leverage resources and knowledge to reduce burden on the public sector, increase health-care-system capacity, and ensure access.

The Population Council supports the Total Market Approach and is invested in generating the evidence needed to facilitate introduction of the PVR in sub-Saharan Africa and India. Researchers have been: assessing interest in and support for the PVR among decision-makers who determine which products are made available in their countries; determining acceptability of the ring among breastfeeding women, partners, providers; and streamlining pathways for introduction. With the addition of the PVR to the World Health Organization's Essential Medicines List, local regulatory authorities now have more evidence supporting the value of introducing the PVR within their family planning programs.

Suggested citation: Population Council. 2016. "Delivering Contraceptive Vaginal Rings to Breastfeeding Women." New York: Population Council.

This publication is made possible by the generous support of the American people through the United States Agency for International Development (USAID). The contents are the responsibility of the Population Council and do not necessarily reflect the views of USAID or the United States Government.

\section{REFERENCES}

1. Sedgh, G. et al. "Intended and unintended pregnancies worldwide in 2012 and recent trends, Guttmacher Institute. Available at: http://onlinelibrary.wiley.com/doi/10.1111/j.1728 4465.2014.00393.x/full. Accessed 27 July 2016.

2. Carr, S.L., et al. 2015 "Safety of the progesterone-releasing vaginal ring (PVR) among lactating women: A systematic review," Contraception. 11 April. [Epub ahead of print.] Sivin, l., et al. 1997. "Contraceptives for lactating women: A comparative trial of a progesterone-releasing vaginal ring and the copper T 380A IUD," Contraception 55(4): 225-232. Diaz, S., G. Rodriguez, G. Marshall, G. del Pino, M.E. Casado, P. Miranda, et al. 1988. "Breastfeeding pattern and the duration of lactational amenorrhea in urban Chilean women, Contraception 38. 37-51.

Diaz, S, G. Rodriguez, O. Peralta, P. Miranda, M.E. Casado, A.M. Salvatierra, et al. 1988. "Lactational amenorrhea and the recovery of ovulation and fertility in fully nursing Chilean women, "Contraception 38. 53-67.

Kennedy, K.I., R. Rivera, and A.S. McNeilly. 1989. "Consensus statement on the use of breastfeeding as a family planning method," Contraception 39: 477-496. Kennedy, K.I. and C.M. Visness. 1992. "Contraceptive efficacy of lactational amenorrhoea," Lancet 339: $227-230$.

Kennedy, K.I. 2002. "Efficacy and effectiveness of LAM," Adv Exp Med Biol 503: 207-216. Valdés, V, M.H. Labbok, E. Pugin, and A. Perez. 2000 "The efficacy of the lactational amenorrhea method (LAM) among working women," Contraception 62: 217-219. Diaz, S., P. Miranda, A. Brandeis, H. Cardenas, and H.B. Croxatto. 1991. "Mechanism of action of progesterone as contraceptive for lactating women," Annals of N Y Acad Sci 626: 11-21. Fabic, M.S. and Y. Choi. 2013 "Assessing the quality of data regarding use of the lactational amenorrhea method, Studies in Family Planning 44: 205-221. UNICEF: Breastfeeding. Available at: http://www.unicef.org/nutrition/index_24824.html. Accessed 25 July 2016.

Sustainable Development Goals Platform. Available at:

https://sustainabledevelopment.un.org/?menu=1300. Accessed 9 August 2016. 